\title{
MOULD FLOW AND STRUCTURAL ANALYSIS OF INJECTION MOULD TOOL FOR HOOTER BODY COVER COMPONENT
}

\author{
Allwin Arulanandan. $\mathrm{K}^{1}$, Ramesha. $\mathrm{N}^{2}$ \\ ${ }^{1}$ Dept. of PG studies, Govt. Tool Room \& Training centre, Mysore, Karnataka, India-570016 \\ ${ }^{2}$ Dept. of PG studies, Govt. Tool Room \& Training centre, Mysore, Karnataka, India -570016
}

\begin{abstract}
Injection moulding is process of manufacturing plastics products from both thermo and thermosetting plastic materials. This paper presents the part modeling, design of core-cavity and side core by using SOLID WORKS 2012, the mould flow analysis is carried out by MOLD FLOW ADVISOR 2105 and static structural analysis performed using ANSYS V14.5. The mould tool is of single cavity mould and material planned for producing the component is polypropylene ( $p p$ )
\end{abstract}

Keywords: injection moulding, core-cavity, plastic material, mould flow and static structural analysis.

\section{INTRODUCTION}

In the Injection molding process where melted plastic material is forced under pressure into a mould tool where it is solidified and ejected when the tool opens of the mould. The features of the desired part such as simplest to complex components. The advantages of injection molding are production rate is high, higher tolerances, low cost and reduces scrap cost but investment cost is high. [3]

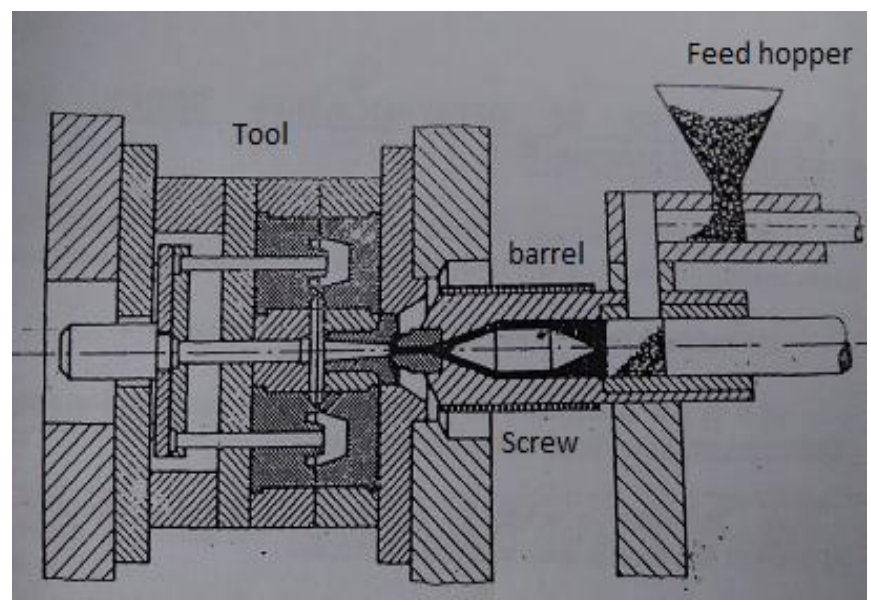

Fig -1: Injection moulding machine

\subsection{Working Cycle of Injection Moulding}

- $\quad$ Mould Tool Closing: Apply Clamping force on tool to close the mould the force is obtained by hydraulic or toggle mechanisms.

- Injection: The molten plastic material is injected under high pressure into the mould.

- Cooling: Cold water is circulated on core-cavity to maintain temperature and prevent tool being seizure.

- $\quad$ Opening of Mould Tool: Clamping force is released and side cores are withdrawn and tool opens.

- $\quad$ Ejection: Removing the finish part from the tool. [3]

\section{MATERIAL}

Hooter body covers are plastic housings for mounting hooter in control panel. The material used for producing the hooter body cover is polypropylene to establish High tensile strength, excellent thermal insulating properties, excellent dielectric properties, Long life span. [4]

\subsection{Properties of Polypropylene [5]}

Shrinkage: $1.5 \%$

Density of polypropylene: $0.9 \mathrm{~g} / \mathrm{cm}^{3}$

Melt temperature: $220^{\circ}-280^{\circ} \mathrm{C}$

Mould temperature: $30^{\circ}-80^{\circ} \mathrm{C}$

\section{METHODOLOGY}

The component is modeled using SOLID WORKS 2102 and component as 8 small rectangular slots as shown in figure-2 other details are given below.

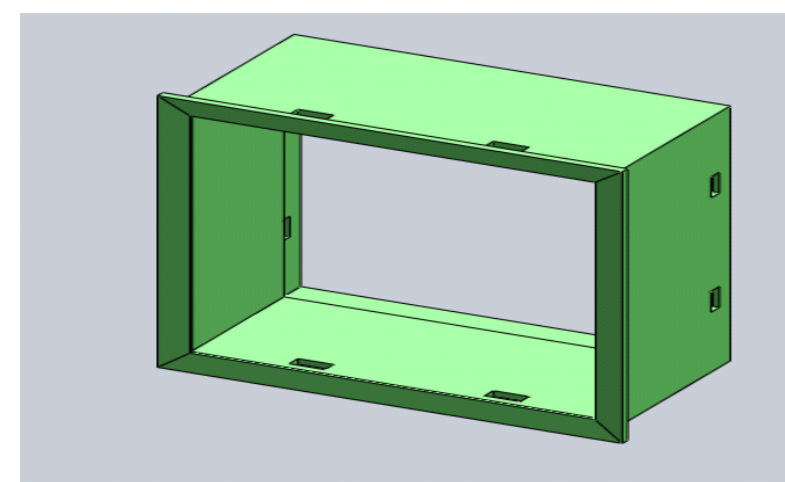

Fig -2: Model of hooter body cover

1. Volume of model: $34727.03 \mathrm{~mm}^{3}$

2. Surface area of model: $38910 \mathrm{~mm}^{3}$

3. Weight of component: 31.25 grams.

4. Number of cavity: Single cavity.

5. Minimum and maximum wall thickness: $2 \mathrm{~mm} \& 0.6 \mathrm{~mm}$.

6. Type of mould: Three plate mould. 


\section{MOULD FLOW ANALYSIS}

The mould flow analysis is used to obtain the subsequent helpful factors:

$>$ To achieve the thin uniform wall thickness and good stability.

$>$ To spot out and eradicate sink marks, weld lines and air traps.

$>$ To decide the proper injection location for the component.

$>$ To spot out the high temperature in the mould tool and introduce the cooling system.[1][2]

The MOLD FLOW ADVISOR 2015 software is used suggest mould filling for the component and these results are obtained after carrying out the study.

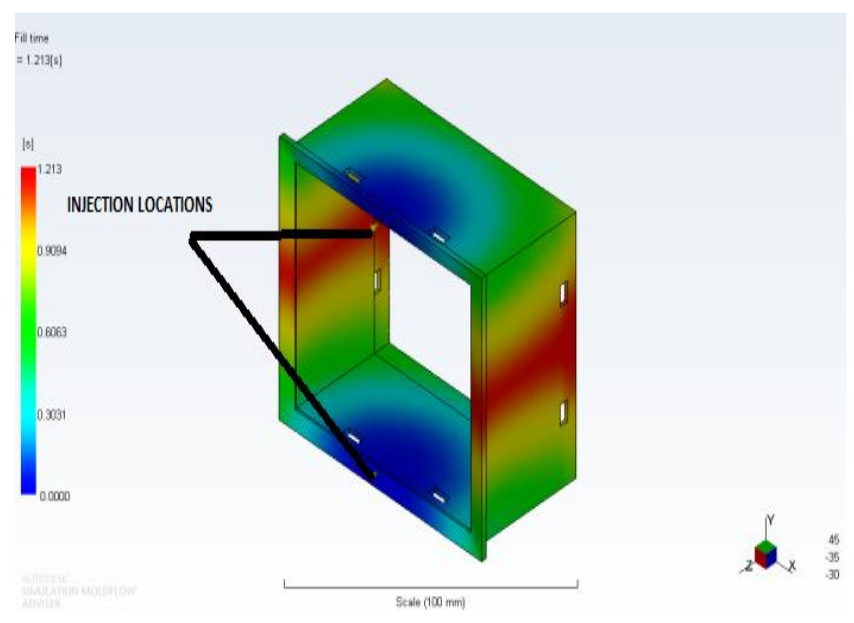

Fig -3: Fill time results

A. The best injection location is been identified. In the fig-3 the two points of injection location are provided in order to avoid pressure drop and material will flow easily to the last point in cavity. The time required to fill the cavity is found to be 1.2 secs.

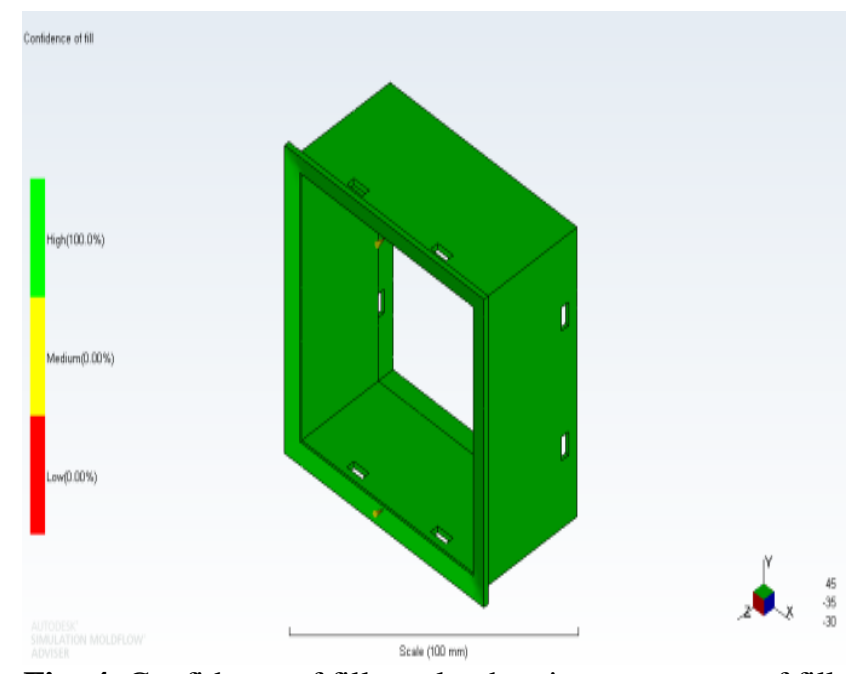

Fig- 4: Confidence of fill results showing percentage of fill.
B. The confidence of fill results is given in figure- 4 which describes that the material will fill the whole cavity at higher efficiency depending upon the temperature and pressure.

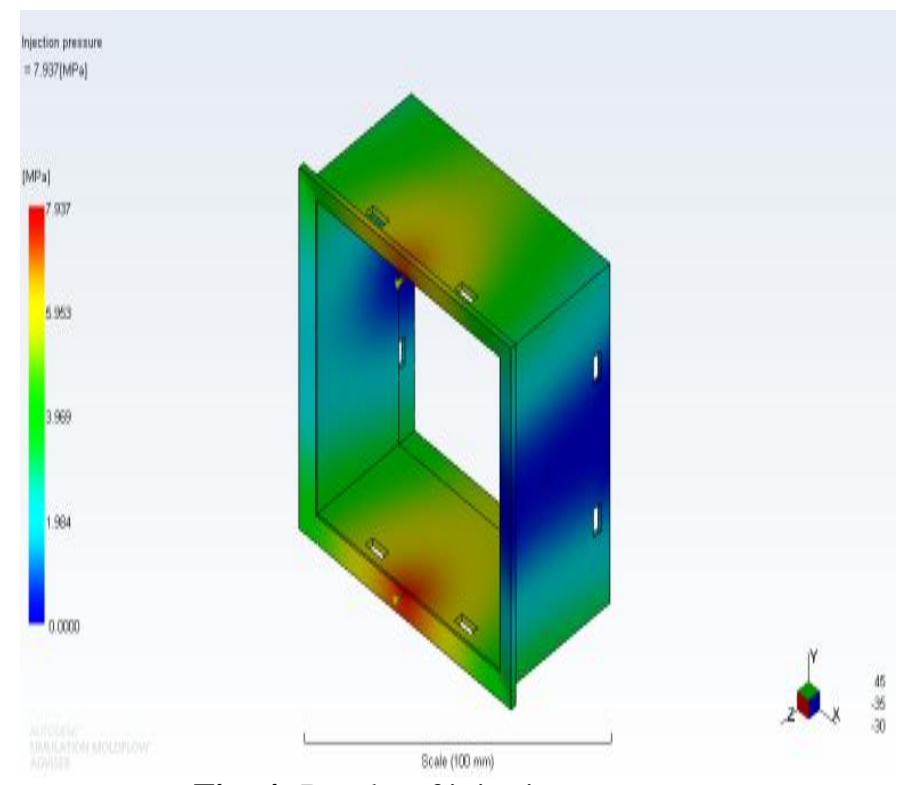

Fig -4: Results of injection pressure.

C. The injection pressure found to be $7.937 \mathrm{Mpa}$ results are given in figure- 4 . From the mould flow analysis the best injection location is observed.

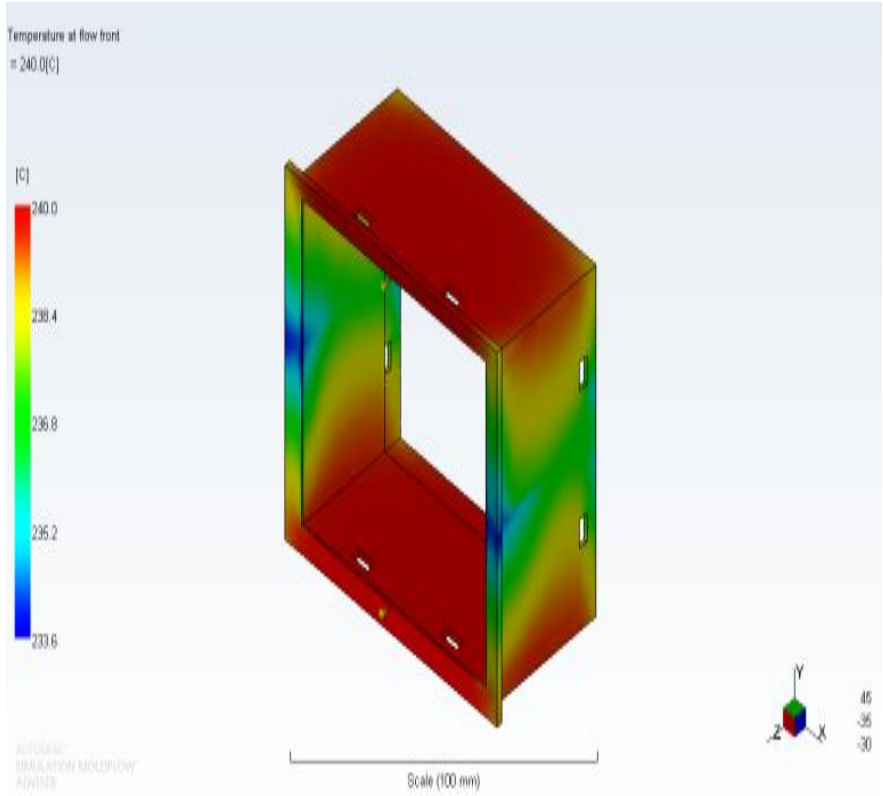

Fig -5: Results flow front temperature

D. The flow front temperature results shown in figure-5. The area that shows of low temperature in blue color and the area of high temperature in red color and flow front temperature is $240^{\circ} \mathrm{C}$. 


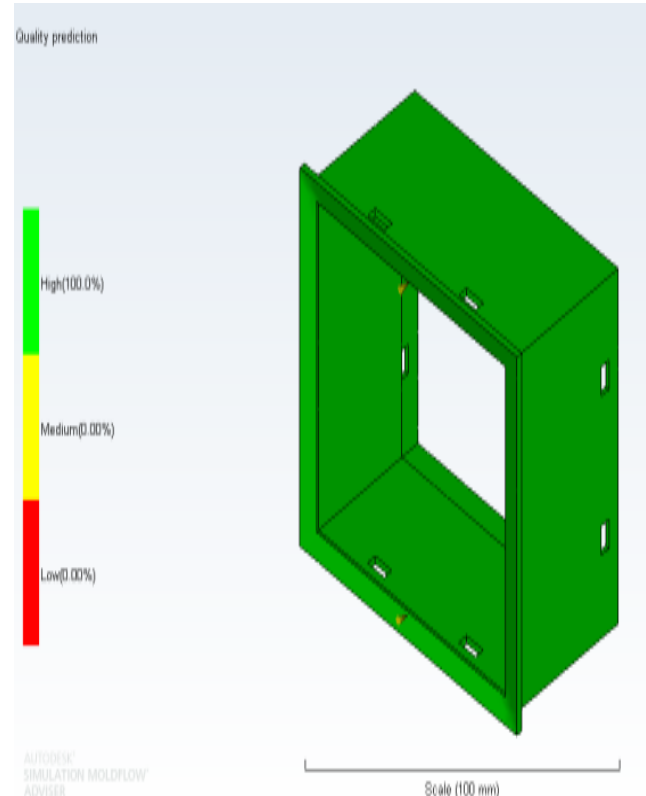

Fig- 6: results of quality prediction

E. The quality prediction results are shown in figure-6, in these results green color represents highest quality.

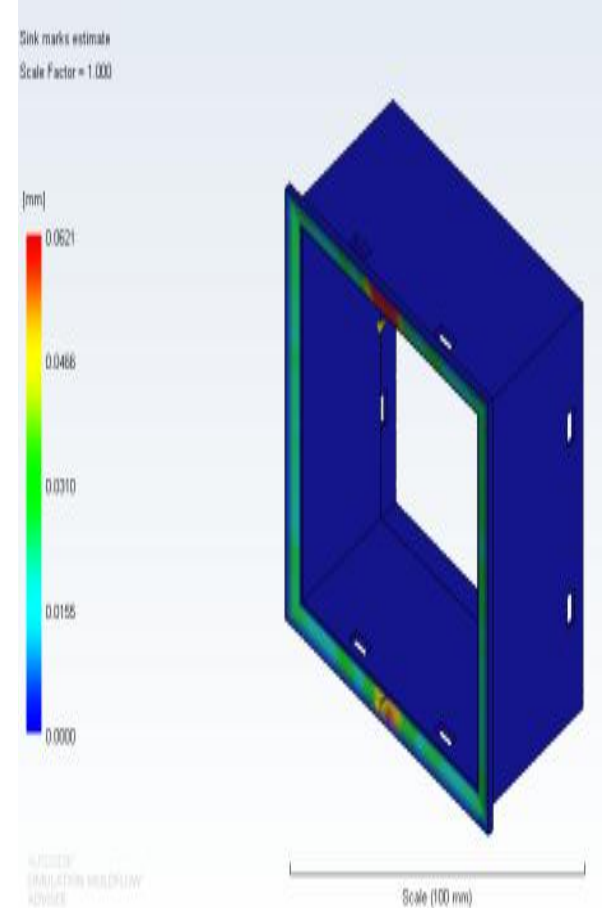

Fig- 7: Results of sink marks.

F. The sink marks results are shown in figure-7and found maximum at injection location this can be avoided gating system.

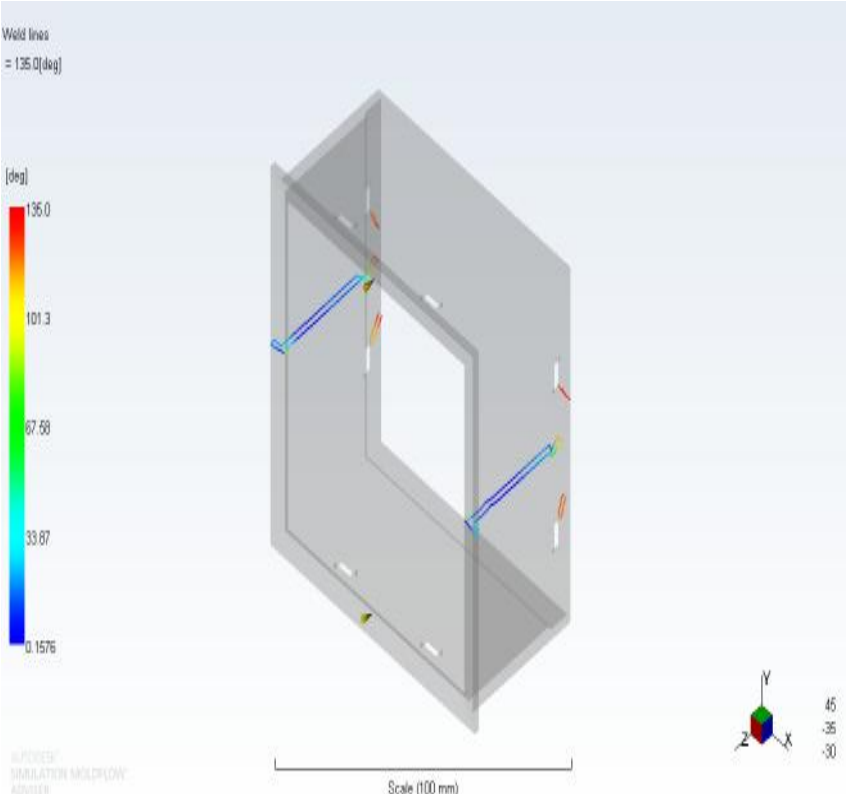

Fig- 8: Results of weld lines

G. Weld lines results are observed in figure- 8 these lines are area which is weak and can be prevented by increasing the pressure of injection and increasing the area of gate.

\section{INJECTION MOULD TOOL}

The injection moulding tool consists of fixed half, movable half and ejector assembly. Here the tool is of three plate mould that is fixed plate, floating plate and movable plate.

Fixed plate is been clamped to machine bed and movable plate is fixed on other side of machine where the clamping force is applied. [6]

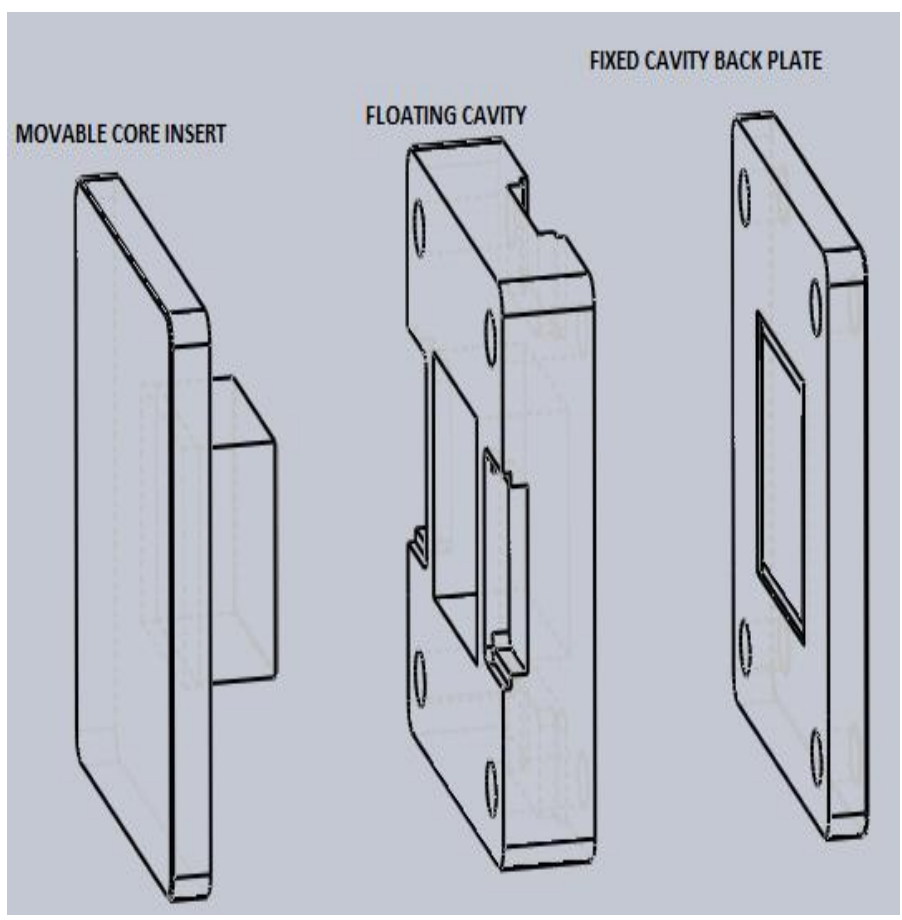

Fig- 9: Three plate mould 


\section{CORE AND CAVITY}

The mould is separated into three halves that is core, cavity and floating cavity as shown in figure- 9 along with 4 side cores in order to obtain the slots in component.

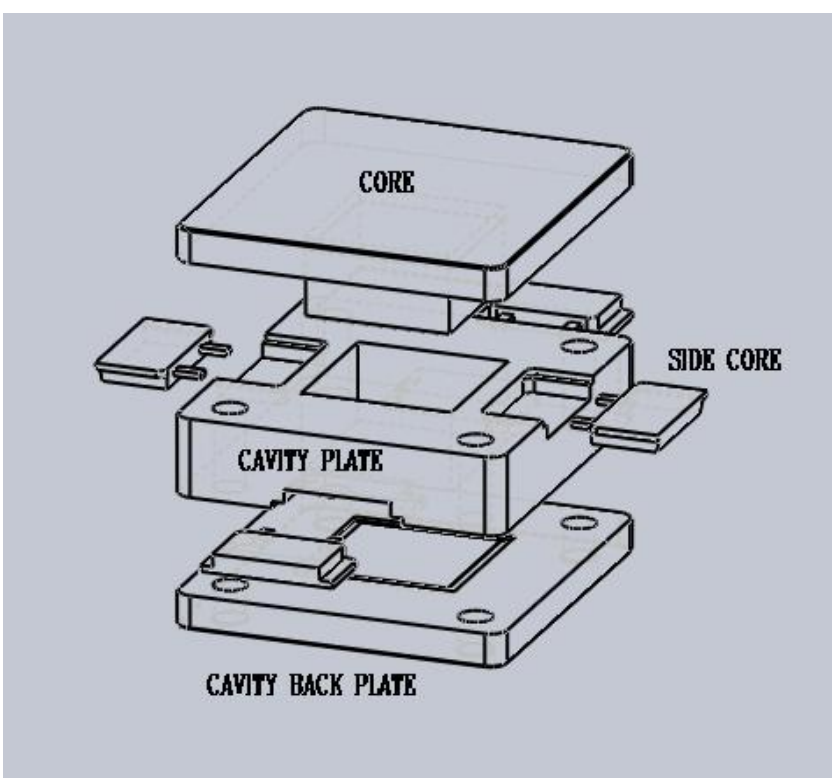

Fig-10: Core, cavity and side cores

\section{STRUCTURAL ANALYSIS}

The structural analysis is carried out on core cavity to obtain strength of the core-cavity, tool life, ability of the material and to check that the stress should not yield to maximum limit of material. Clamping force is calculated and applied over the core-cavity and results obtained are been shown below.

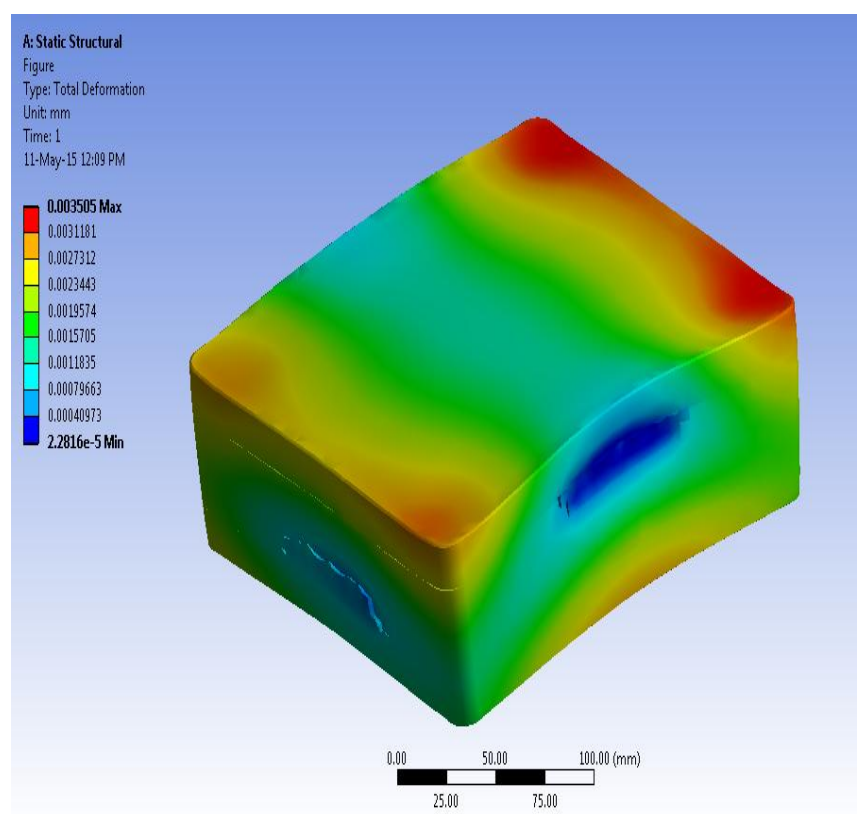

Fig -11: Results of Deformation of core-cavity

7.1 Deformation results of the core-cavity are shown in the figure-11 and it found to be $0.003505 \mathrm{~mm}$ nominal.

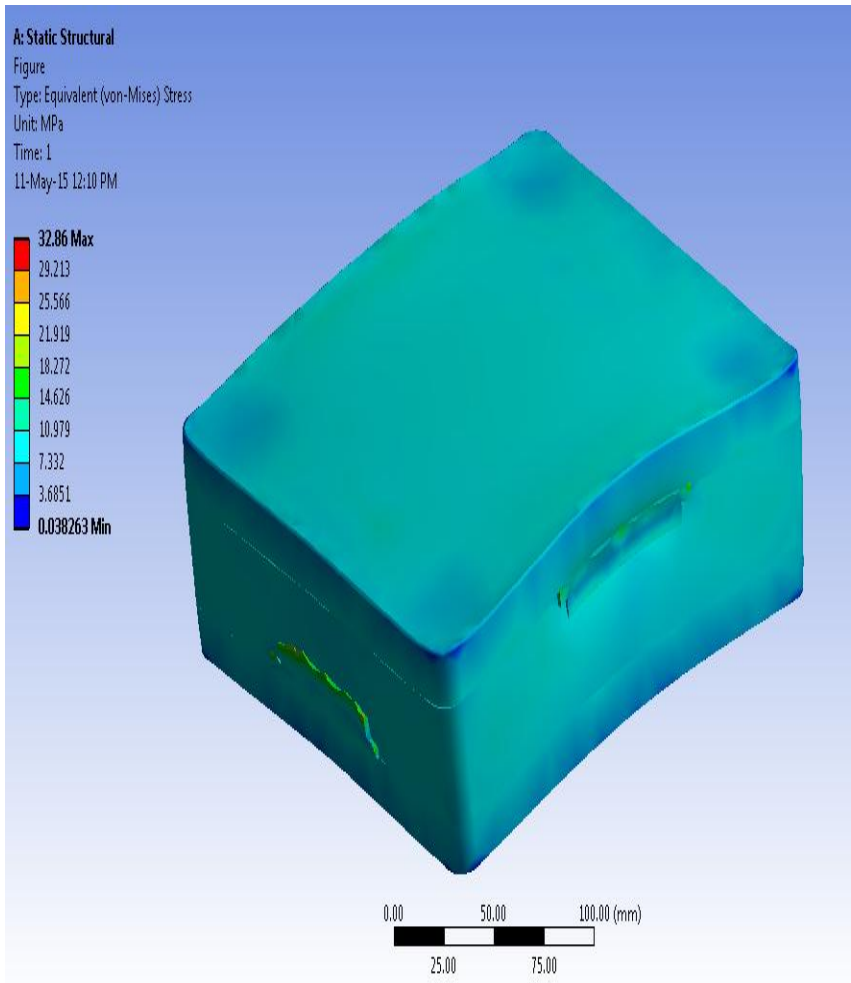

Fig-12: Results of von mises stress induced on core-cavity

7.2 The result of stress induced on core-cavity is $32.86 \mathrm{Mpa}$ as shown in the figure-12 which is less than yield stress of the material so the design is safe.

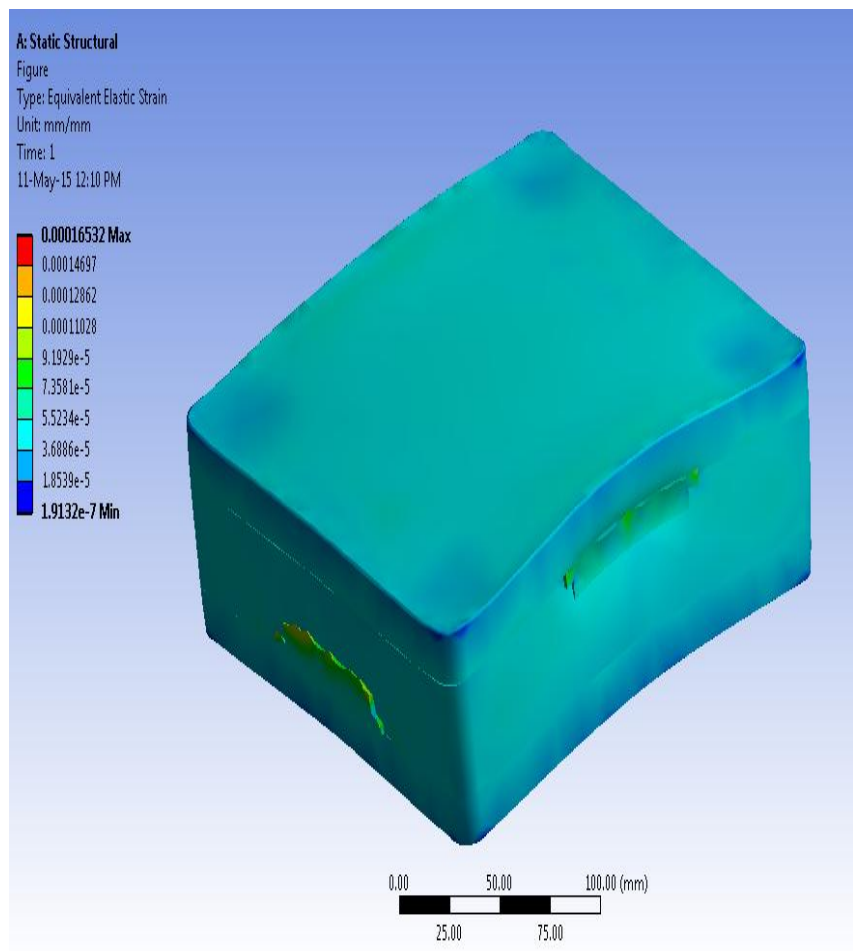

Fig-10: Results of elastic strain on core-cavity

7.3 The results of strain on core-cavity are found to 0.00016532 . 


\section{CONCLUSION}

The result obtained from mould flow analysis clearly gives the ideas on the important technical consideration before proceeding to mould design and injection moulding machine. The analysis affords information on fill time 1.2 secs. injection pressure is $7.937 \mathrm{Mpa}$ flow front temperature is $240^{\circ} \mathrm{C}$ and various parameters. Static structural analysis on core-cavity by applying force that shows about deformation is $0.003505 \mathrm{~mm}$, stress is $32.86 \mathrm{mpa}$ and strain is 0.00016532 . So that the design is safe and it will be helpful for designer to produce good quality mould considering all aspects in design. The plastic flow analysis is carried out using MOLD FLOW ADVISOR 2014and ANSYS V14.5 software's. All the results are been analyzed and necessary action is be taken while designing the mould tool.

\section{REFERENCES}

[1]. Peter Kennedy, Rong Zheng, Flow Analysis of Injection Molds, 2nd Ed., Hanser Publications, Cincinnati, U.S.A, 2013.

[2]. Ashutosh Modi, Prof. K.A. Rade, S.S. Kulkarni, Design enhancement for an injection mold using inputs from flow analysis, IJAERS, Vol. II, Issue III, April-June, 2013.

[3]. Injection Mould Design, R.G.W. Pye.

[4]. Injection Mould Design, Rapra.

[5]. Technical Directory on Design and Tooling for Plastics, CIPET.

[6]. "Material for injection moulding" branisler Dublea Frantisek-2012 